\title{
Research on the Evaluation Index System of Teachers' Training Quality in Higher Vocational Colleges
}

\author{
Tao Liu*, Han Zheng \\ Guangdong Vocational College of Post and Telecom, Guangzhou 510630, Guangdong Province, China \\ *Corresponding author: Tao Liu, $913621292 @ q q . c o m$
}

\begin{abstract}
In order to improve teachers' comprehensive ability and quality, it is extremely important to conduct training for teachers. When higher vocational colleges train teachers, the construction of an evaluation index system for the training quality is important to determine the training effect, point out the training direction, and deepen the training content, thus laying the foundation for systematic and reasonable trainings. Based on Kirkpatrick model and teachers' professional development evaluation model, this article expounds the specific means of the evaluation index system of teachers' training quality from six first-class indicators in order to lay the foundation for the improvement of teachers' training quality.
\end{abstract}

Keywords: Higher vocational colleges; Teacher training; Quality evaluation; Construction of index system

Publication date: June 2021; Online publication: June 30, 2021

\section{Introduction}

At present, the state attaches great importance to the training of teachers. The Ministry of Education has also issued a series of policies to improve the quality of teachers' training. However, there are still several problems in the quality of teachers' training, such as unsuitable contents, a relatively single training method, inadequate monitoring of training quality, and so on. In order to solve these problems, it is necessary to create a systematic and reasonable training system, clarify the evaluation indicators, determine the training effect, and reach a conclusion of whether the training has played a corresponding role. The quality evaluation of teachers' training is complex; thus, it is important to view it from different dimensions, such as the purpose, project, means, and effect. In fact, these dimensions are currently in a broken state. Only by continuously improving the quality evaluation system and building a more operable set of quality evaluation indicators, then the evaluation requirements of teachers' training quality can be met. Therefore, from the perspective of teachers' training organizations in universities, a complete and systematic primary evaluation index system is built, which is of great help to the improvement of teachers' training quality and the standardization of their training.

2. Theoretical basis for the construction of an evaluation index system of teachers' training quality in colleges and universities

\subsection{Kirkpatrick model}

Kirkpatrick model has a far-reaching impact in the field of evaluation. At present, the evaluation model is widely used in the quality evaluation of industrial and commercial training abroad. From the perspective of behavior, the model comprehensively evaluates the response, learning style, results, and behavior of training colleges. These four levels of evaluation are different. 
The first is the evaluation of response. The evaluation mainly makes an in-depth analysis of the training attitude and purpose of the training teachers, and then similarly makes a comprehensive evaluation of the training scheme, training method, training management, and service of the teachers. This is not only the most basic evaluation in the training system, but also an evaluation of the external form. The second is the evaluation of learning style. This evaluation method mainly evaluates the results of teachers' participation in training. Specifically, it includes the mastery of training knowledge and training skills. This evaluation mainly reflects what teachers have learned. The third is the evaluation of teachers' behavior. The evaluation of behavior mainly refers to whether teachers really apply the learned ideas and methods to their teaching practices after receiving training and whether it helps in teachers' work effect so as to significantly improve their work performance, paying more attention to teachers' ability in transferring posts and their change in attitude after training. Finally, the evaluation of teaching results. After receiving training, teachers would naturally apply what has been harvested in their training to their actual teaching practices, which significantly improves the personal effectiveness of teachers. However, this effect is reflected in the improvement of teaching quality, and there is no way to evaluate it vividly. Therefore, it is necessary to summarize and evaluate in time. The model has rich connotation and diversified forms. It focuses on all aspects in teachers' training, which is helpful to the rectification of follow-up training programs.

\subsection{Teachers' professional development evaluation model}

Although the Kirkpatrick model can be widely used in various types of job training, it is mainly used in industrial and commercial training as mentioned above. In view of that, it is feasible but insufficient to apply it to teachers' training. In order to solve this disadvantage, it is necessary to improve and change its contents based on the characteristics of teachers' professional development as well as replace the four-level evaluation method with a five-level model. The five levels of teachers' professional development evaluation model mainly include teachers' response to training, teachers' learning effect, teachers' dynamic changes, teachers' participation in work, and students' learning effect. The response evaluation is concerning the preference and acceptance of the teachers that participate in the training program. The learning effect of teachers mainly refers to the results obtained by teachers after receiving training, which may include the harvest of knowledge, ideas, models, methods, and other aspects. The dynamic changes of teachers refer to the changes that were made after learning new knowledge and skills. Achievement evaluation refers to the effect from the use of the harvested results to evaluate the original teaching work. Learning effect evaluation refers to a change for teachers but expounds the beneficial impact of the improvement of teachers' professional skills on their students from the students' perspective. The teachers' professional development evaluation model is more comprehensive.

\section{Construction process of the evaluation index system}

\subsection{Literature search and data integration}

The purpose of searching literatures is to analyze and determine the elements which affect the quality of teachers' training, its evaluation effect, the connotation of quality evaluation, and the diversified quality evaluation tools so as to put forward systematic and reasonable suggestions. This step mainly involves the query of relevant literatures in regard to the above two models and the analysis of several models which are frequently used for quality evaluation in China. Then, the condition model, performance model, and benchmark model are determined according to different evaluation indicators and evaluation emphases along with the relationship between performance evaluation cost and final output. Literature search can increase the understanding of the evaluation models, thus allowing an in-depth analysis of the early, middle, and late stage of teachers' training. In addition to literatures on the internet, it is also important to take into 
account of the documents from different countries and regions so as to deeply understand the relevant policy requirements of teachers' training quality. When analyzing government documents, it is essential to classify the indicators required in the documents, frame the framework of evaluation index system, and preliminarily explain the relevant indicators.

\subsection{Field research}

Field research is mainly to provide corresponding basis for the construction of the evaluation index system. At present, the most commonly used methods in field research are questionnaire surveys and interviews. In the evaluation of teachers' training, questionnaire surveys are mainly used to understand the cognition of teachers and other subjects for the evaluation of training quality. Much information can be derived from these surveys, such as the overall situation of training, the types and quantity of teachers participating in training, the means of improving the quality of training, and so on. This is because these questions are more complex, and it is not possible to achieve the purpose of the survey in just a few words. Therefore, the use of questionnaire surveys is the simplest yet an effective way in field research. The other is the interview method. The main body of the interview includes the person in charge of the training and the teachers participating in the training. Through face-to-face conversation, it is possible to better understand the attitude of these subjects towards training, thus improving the evaluation and making the feedback more authentic.

\subsection{Practical application and inspection}

After the completion of literature search and field research, the next stage is the practical application. In the process of practice, it is necessary to conduct meetings for discussions in order to understand the problems faced by teachers participating in the training. With that in mind, the suggestions received from relevant experts can be used to revise and improve the indicators of teachers' training quality repeatedly, and eventually build a perfect evaluation system.

\section{Composition of the evaluation index system of teachers' training quality in colleges and universities}

\subsection{Organization and management}

Organization and management are important to complete training projects and improve training quality. When carrying out training, corresponding organization and training system should be formulated. Then, secondary indicators should be constructed. The secondary indicators include the management team and system construction. The specific observations of the management team include the importance of leaders, the local teachers' training planning and training projects, the supervision team, as well as the logistics support team. The evaluation criteria are that the leaders attach great importance to it, have clear responsibilities, communicate closely with the management organization, accurately grasp the local teachers' training planning and training projects, establish a 3-5 person supervision team with the participation of front-line teachers, carry out the supervision and evaluation of the training process, as well as form a complete logistics support team, including the project leader, full-time management personnel, and head teachers. The methods used for the evaluation are consulting the archives and discussing with the person in charge as well as the students. The specific observations of the system construction include teaching management, teaching quality monitoring, student assessment and evaluation management, training file management and other systems, accommodation, security, and other related systems, as well as special management system for training funds. The evaluation standards include having a complete and feasible teaching management, teaching quality monitoring, student evaluation management, training file management and other systems, sound accommodation, safety guarantee, and other relevant systems, 
emergency plan, as well as special management system for training funds to ensure that the funds can be used for special purposes. The method for the evaluation is to consult the archives.

\subsection{Scheme design}

The design of training scheme is not only an important content, but also an important link before carrying out various training practices. High quality design can significantly improve the effectiveness of training. When designing the training program, actual research, scientific and reasonable training program, as well as relevant experts are required if necessary.

\subsection{Faculty team}

In teachers' training, most of the training staffs and participants are teachers. Therefore, the structure and level of the faculty team are directly related to the flow of this training. Hence, before training, it is vital to build a high-level and reasonably structured team of teaching staffs.

\subsection{Resource allocation}

In order to ensure the quality of teachers' training, training organizations need to prepare sufficient training resources, encompassing two aspects: curriculum resources and practice resources.

\subsection{Training implementation}

Training implementation is the core and the largest part of the whole evaluation system. The process of training implementation mainly includes two parts; the first part involves teaching activities, and the other part is the monitoring of teaching activities. After the completion of training, training organization personnel need to follow-up with the training work in a timely manner in order to correctly gauge the feelings of the trainees; then, make subsequent corrections based on the feedback and suggestions provided by the trainers.

\subsection{Evaluation and reflection}

After training, it is necessary to summarize the training contents, find out relevant problems, and perform salary adjustments based on the problems fed back so as to accumulate sufficient training experience and provide appropriate reference for teachers that would participate in the training in the future.

\section{Conclusion}

In order to ensure the effective development of teachers' training, there is a need to reform the traditional training. First of all, teachers need to create a systematic and reasonable evaluation of their training work so as to stimulate the enthusiasm of teachers' training organization personnel. Then, the training program should be optimized while carrying out follow-up evaluations and tracking work in order to promote the professional growth of teachers.

\section{Disclosure statement}

The authors declare that there is no conflict of interest.

\section{References}

[1] Dong Z, Zhao B, 2020, Research on the Construction of Adult Education and Training Quality 
Evaluation System. China Adult Education, (16): 29-32.

[2] Gu C, Cao W, Qiu J, et al., 2020, Study on the Construction of Teaching Quality Evaluation Index System for Standardized Training of General Practitioners. China General Medicine, 23(S1): 14-17.

[3] Yuan B, 2020, Research on the Construction of Training Quality Evaluation System in Basketball Training Institutions. Zhongbei University.

[4] Yao Q, Zhang Y, 2019, Construction of Resident Standardized Training Evaluation System Based on Coriolis and CIPP Model. Health Vocational Education, 37(12): 138-140. 